chronic arthropathy. Periarticular calcification, which is a feature of both these conditions, is not, however, a feature of dialysis arthropathy. Similarly, there was no evidence of chondrocalcinosis or, hence, pseudogout in these patients. As bone biopsies were not performed in these patients the possibility that accumulation of aluminium in bone contributed to this arthropathy cannot be excluded.

The results of this study of patients receiving long term treatment with haemodialysis show that many patients develop a progressive and often severe arthropathy that is commonly complicated by recurrent carpal tunnel syndrome. Some of the patients became severely disabled from this arthropathy, which therefore must be regarded as a major complication of long term treatment with haemodialysis. As this arthropathy does not develop in patients with longstanding chronic renal failure who are not receiving dialysis it is probably due to the haemodialysis process itself rather than uraemia. Further studies are needed urgently to determine the cause of this dialysis arthropathy and establish whether inflammatory responses induced by dialysis could lead to this widespread deposition of amyloid.

\section{References}

1 Mirahmadi KS, Coburn JW, Bluestone R. Calcific periarthritis and hemodialysis. JAMA 1973;223:548-9.

2 Llach F, Pederson JA. Acute joint syndrome and maintenance hemodialysis. Proceedings of the Clinical Dialysis and Transplant Forum. Washington DC, Georgetown, 1979:17-22.
3 Massry SG, Bluestone R, Klinenberg JR, Coburn JW. Abnormalities of the musculoskeletal system in hemodialysis patients. Semin Arthritis Rheum 1975;4:321-49.

4 Bailey GL, Griffiths AJL, Mocelin AJ, Gundy DH, Hampers CL, Merrill JP. Avascular necrosis of the femoral head in patients on chronic hemodialysis. Trans Am Soc Artif Intern Organs 1972;18:401-4.

5 Rosenfield N, Rascoff JH. Tendon ruptures of the hand associated with renal dialysis. Plast Reconstr Surg 1980;65:77-9.

6 Matthews $M$, Shen FH, Lindner A, Sherrard DJ. Septic arthritis in haemodialyzed patients. Nephron 1980;25:87-9.

7 Brown EA, Gower PE. Joint problems in patients on maintenance haemodialysis. Clin Nephrol 1982;18:247-50

8 Jain UK, Cestero RUM, Baum J. Carpal tunnel syndrome in patients undergoing maintenance hemodialysis. FAMA 1979;242:2868-9.

9 Deimez JA, Hottman B, Sicard GA, Goldberg AP, Harter HR. Peripheral nerve entrapmen syndromes in chronic haemodialysis patients. Nephron 1982;30:118-23.

10 Schwarz A, Keller F, Syfert S, Poll W, Molzahn M, Distler A. Carpal tunnel syndrome: a majo complication in long-term haemodialysis patients. Clin Nephrol 1984;22:133-7.

11 Goldstein S, Winston E, Chung TJ, Chopra S, Pariser K. Chronic arthropathy in long-term hemodialysis. Am 7 Med 1985; 78:82-6.

12 Charra B, Calemard E, Uzan M, Terrat JC, Vanel T, Laurent G. Carpal tunnel syndrome, shoulder pain and amyloid deposits in long-term haemodialysis patients. Kidney Int 1984; 26:549.

13 Bergada E, Montoliu J, Bonal J, Subias R, Lopez Pedret J, Revert L. Carpal tunnel syndrome with local and articular amyloid deposits in haemodialysis patients. Kidney Int 1984;26:579.

14 Blake DR, Hall ND, Bacon PA, Dieppe PA, Halliwell B, Gutteridge JMC. The importance of iron in rheumatoid disease. Lancet 1981 ;ii:1142-4.

15 Dinarello CA. Interleukin-1 and the pathogenesis of the acute phase response. $N$ Engl f Med 1984;311:1413-8.

16 Bywaters EGL, Dixon A St J, Scott JT. Joint lesions of hyperparathyroidism. Ann Rheum Di 1963;22:171-87

17 Rubin LA, Fam AG, Rubenstein J, Campbell J, Saiphoo C. Erosive azotemic osteoarthropathy. Arthritis Rheum 1984;27:1086-94.

18 Dieppe PA, Crocker P, Huskisson EC, Willoughby DA. Apatite deposition disease. Lance 1976;:266-9.

19 Hoffman GS, Schumacher HR, Paul H, et al. Calcium oxalate microcrystalline-associated arthritis in end-stage renal disease. Ann Intern Med 1982;97:36-42.

(Accepted 24 October 1985)

\title{
Internal urinary sphincter in maintenance of female continence
}

\author{
E VERSI, L D CARDOZO, J W W STUDD, M BRINCAT, T M O'DOWD, D J COOPER
}

\begin{abstract}
The integrity of the bladder neck was assessed in 98 continent women. Radiological and physiological evidence showed that half of these women had an incompetent bladder neck, but they were still continent. These data devalue the urodynamic finding of an incompetent bladder neck as an indication for surgery for incontinence and question the physiological importance of the internal sphincter.
\end{abstract}

\section{Introduction}

Traditionally, it has been taught that urinary continence is maintained by the internal and external sphincters. Ellis claims that in women the internal sphincter (the bladder neck) is the more important, ${ }^{1}$ and in Cunningham's Textbook of Anatomy it is stated

\footnotetext{
Urodynamic Unit, King's College Hospital and Dulwich Hospital Menopause Clinic, Dulwich Hospital, London SE22

E VERSI, DPHIL, $\mathrm{MB}$, research fellow

L D CARDOZO, MD, MRCOG, consultant gynaecologist

J W W STUDD, MD, MRCOG, consultant gynaecologist

M BRINCAT, MRCS, LRCP, research fellow

T M O'DOWD, BAO, MRCOG, research fellow

Computer Unit, King's College Hospital School of Medicine and Dentistry, London SE5

D J COOPER, MSC, DPHIL, senior analyst
}

Correspondence to: Dr L D Cardozo, Department of Obstetrics and Gynaecology, King's College Hospital School of Medicine and Dentistry, London SE5. that "urine is held at the level of the bladder neck." Opening of the bladder neck in response to stress-for example, increase in intraabdominal pressure during a cough-has been considered to be abnormal $^{3}$ and has been used as an indication for surgery in patients complaining of stress incontinence (S Rees, T P Stephenson, C J Richards. The results of colposuspension. Proceedings of the International Continence Society's fourteenth meeting, Innsbruck, 1984). The aim of this paper is to show that incompetence of the bladder neck may be a common variant of normal and should not therefore be regarded as a urodynamic abnormality. This was achieved by radiological screening and interpretation of urethral pressure profilometry under stress.

\section{Patients and methods}

Ninety eight women presenting with symptoms of the climacteric, not incontinence, were recruited for this study from the Dulwich Hospital Menopause Clinic. They were all found to be continent on pad testing ( $E$ Versi, L D Cardozo. One hour single pad test as a simple screening procedure. Proceedings of the International Continence Society's fourteenth meeting, Innsbruck, 1984) and normal urodynamically (uroflowmetry and videocystourethrography ${ }^{4}$ ).

Each patient had her bladder filled to capacity $(400-600 \mathrm{ml})$ with Urografin 150 at room temperature, which was then screened radiologically using an image intensifier. The bladder neck was viewed in the erect oblique position. At the same time intravesical and intra-abdominal (rectal) pressures were recorded with the use of $1 \mathrm{~mm}$ manometer tubing, filled with saline, attached to Statham Gould transducers. This system enabled changes in detrusor pressure to be measured even during a cough (by subtracting the intra-abdominal pressure from the intravesical pressure). The integrity of the bladder neck was assessed radiologically and the image recorded on videotape while the patient was asked to cough six times as hard as possible. Incompetence of the internal sphincter was diagnosed when the bladder 
neck was seen to open in response to a cough in the absence of a detrusor contraction and when contrast medium was seen not to pass beyond the midurethral point-that is, incontinence did not occur.

Urethral pressure profilometry was carried out as described by Hilton and Stanton. 5 Patients were in the supine, semilithotomy position and each had $250 \mathrm{ml}$ saline at room temperature instilled into her bladder. Simultaneous pressures of the urethra and bladder were recorded using a 7 French Gaeltec catheter mounted with two solid state depressed transducers with a $6 \mathrm{~cm}$ separation. Initially, the catheter was placed so that both sensors were in the bladder; the catheter was then withdrawn mechanically at a steady speed of $2.5 \mathrm{~mm} /$ second. This resulted in the proximal sensor passing through the urethra, thus obtaining a profile of resting pressure, which was repeated to ensure reproducibility. The catheter was then reinserted and once again withdrawn while the patient was coughing to obtain a pressure profile on coughing (figure).
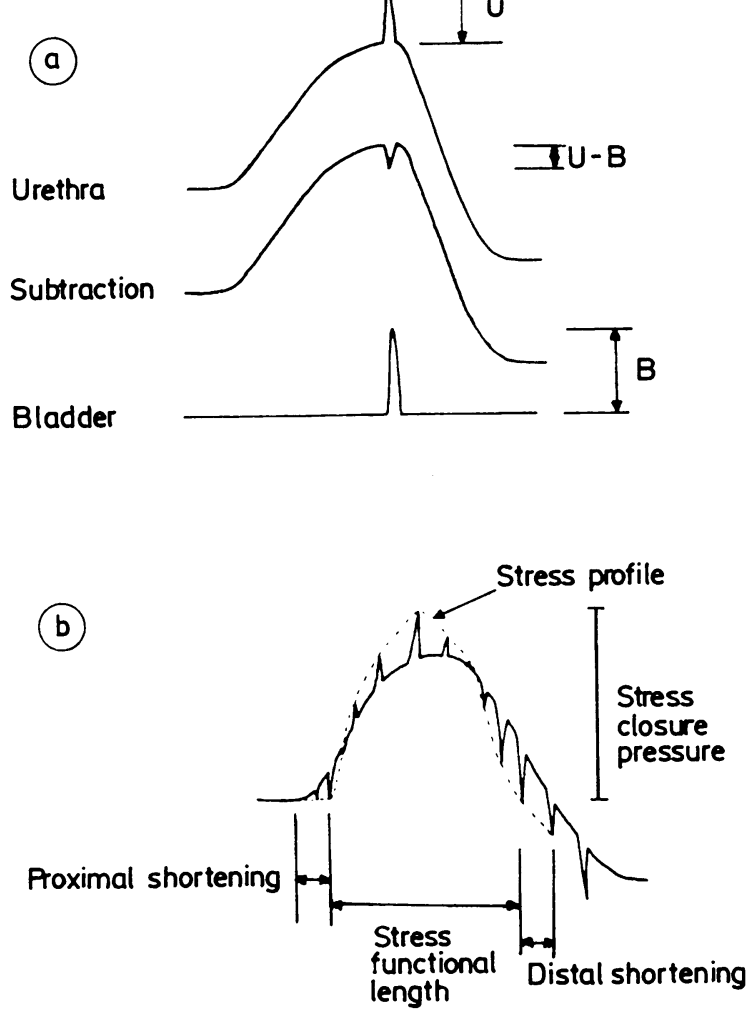

Generation of urethral pressure profile under stress. (a) Urethral pressure profile recorded as catheter is pulled through urethra. Single cough is recorded with pulse registering in urethral $(\mathbf{U})$ and bladder (B) traces, resulting in notch in electronic subtraction trace as cough pulse to urethra is not as great as that to bladder. (b) Subtraction trace of stress pressure profile. Profile is generated by asking patient to cough repeatedly while catheter is withdrawn. Dotted line represents stress profile and proximal shortening results from opening of bladder neck during cough.

The subtraction trace-that is, urethral minus bladder pressure (fig (a))-was used to plot the stress pressure profile (fig $(b)$, dotted line). The proximal deficit in the stress pressure profile is called "proximal shortening." This occurs in patients who have an incompetent bladder neck on coughing. In such cases, when the proximal sensor is in the proximal urethra a cough resulting in opening of the bladder neck causes the two sensors mounted on the catheter to be rendered instantaneously in fluid continuity. Thus the difference in pressure is equalised and recorded as zero in the subtraction trace. In women with a competent bladder neck this should not occur. (All terms used are in accordance with the standardisation committee of the International Continence Society.)

\section{Results}

The table depicts the comparison of data obtained from the imaging and profilometry studies. Radiologically, 50 of the 98 women had an incompetent bladder neck on coughing, and on the basis of the profilometry data 48 had
TABLE I-Comparison of incompetence of bladder neck as seen radiologically with data obtained from urethral pressure profilometry studies. Values are numbers of women in each category

\begin{tabular}{lccc}
\hline & \multicolumn{3}{c}{ Profilometric findings } \\
\cline { 2 - 4 } \multicolumn{1}{c}{$\begin{array}{c}\text { Radiological } \\
\text { findings }\end{array}$} & $\begin{array}{c}\text { No proximal } \\
\text { shortening }\end{array}$ & $\begin{array}{c}\text { Proximal } \\
\text { shortening }\end{array}$ & Total \\
\hline $\begin{array}{l}\text { Competent bladder neck } \\
\text { Incompetent bladder neck }\end{array}$ & 44 & 4 & 48 \\
\hline Total & 6 & 44 & 50 \\
\hline
\end{tabular}

an incompetent bladder neck as shown by the presence of proximal shortening of the stress profile. To compare the agreement of results from the two techniques the kappa index was computed ${ }^{6}: k=\left(P_{o}-P_{e}\right)-\left(1-P_{e}\right)$, where $\mathrm{P}_{\mathrm{o}}=$ observed proportion of agreement and $\mathrm{P}_{\mathrm{e}}=$ expected proportion of agreement. From our data $\mathrm{k}=0 \cdot 8$, which represents substantial agreement between morphological and physiological data. Our results suggest that about half of climacteric women have an incompetent internal sphincter but despite this are still continent.

\section{Discussion}

Function can be surmised from anatomical studies, but physiological data are required for verification. The strong correlation between morphological and physiological data in this study adds weight to our argument that the bladder neck is not essential for maintaining continence in climacteric women. Results of studies carried out by Gosling et al suggested that the orientation of smooth muscle fibre at the bladder neck would, on contraction, probably act to open rather than close the bladder neck. ${ }^{8}$ Competence of the bladder neck is probably achieved by the innumerable elastin fibres found in this area. As half of our patients had a competent bladder neck this clearly has sphincteric function for them, but for the other patients it does not: they use their external sphincteric mechanisms to maintain continence.

It is not clear whether incompetence of the bladder neck is peculiar to climacteric women or if it is a normal finding in women of all ages. Hilton and Stanton, in their small series of 20 asymptomatic women aged between 25 and 74, found proximal shortening of the urethral pressure profile under stress in five women. 5 The weakness of the bladder neck may be initiated or exacerbated by a deficiency in oestrogen in these climacteric women, but as yet no data are available on this.

As incompetence of the bladder neck was seen in half of our sample of continent climacteric women we conclude that this is not a reliable urodynamic finding on which to base the diagnosis of genuine stress incontinence. Incompetence of the bladder neck should not therefore be used as the sole indication for surgery for incontinence.

This work was generously funded by Birthright (Royal College of Obstetricians and Gynaecologists). We thank Sharon Williams for technical help, Trisha Waghorn for typing the manuscript, and $\mathrm{Mr}$ Paul Hilton for advice on the technique of urethral pressure profilometry.

\section{References}

1 Ellis H. Clinical anatomy. 5th ed. Oxford: Blackwell Scientific Publications, 1972.

Romanes GJ, ed. Cunningham's textbook of anatomy. 11 th ed. Oxford: Oxford University Press, 1972:360

3 Abrams P, Feneley R, Torrens M. Urodynamics. Berlin: Springer-Verlag, 1983.

Bates CP, Whiteside CG, Turner-Warwick R. Synchronous cine/pressure/flow cystourethrography with special reference to stress and urge incontinence. $B r \mathcal{F}$ Urol 1970;42:714-23.

5 Hilton P, Stanton SL. Urethral pressure measurement by microtransducer; the results in symptom-free women and in those with genuine stress incontinence. $\mathrm{Br} \mathcal{J}$ Obstet Gynaecol 1983;90:919-33.

6 Cohen J. Weighted kappa: nominal scale agreement with provision for sealed disagreement or partial credit. Psychol Bull 1968;70:213-20.

7 Landis J, Kock GG. The measurement of observer agreement for categorical data. Biometrics 1977;33:159-74.

8 Gosling JA, Dixon JS, Landon RG. The autonomic innervation of the male and female bladder neck and proximal urethra. F Urol 1977;118:302-5.

9 Lapides J. Structure and function of the internal vesical sphincter. $F$ Urol 1958;50:341-53.

(Accepted 22 October 1985) 